\title{
Knowledge, Attitudes and Practices of the University Students on Malaria Prevention in Kavango East, Namibia
}

\author{
Victoria Jacob ${ }^{1} \&$ Vistolina Nuuyoma ${ }^{1}$ \\ ${ }^{1}$ School of Nursing, University of Namibia, Rundu Campus, Namibia \\ Correspondence: Vistolina Nuuyoma, School of Nursing, University of Namibia, PO Box 2874, Rundu, Namibia. \\ Tel: 264-66-268-6056. E-mail: vistolina.nuuyoma@gmail.com
}

Received: December 27, 2018 Accepted: January 10, 2019 Online Published: January 16, 2019

doi:10.5539/gjhs.v11n2p102

URL: https://doi.org/10.5539/gjhs.v11n2p102

\begin{abstract}
Malaria remains a public health concern in Namibia and it is endemic in many regions, including Kavango east region. University students in Kavango east region are at risk of malaria due to bushy environment and the presence of Kavango river, which makes it easy for mosquitoes to multiply. This study aimed to assess and describe knowledge, attitudes and practices of malaria prevention among university students. A quantitative descriptive cross-sectional study was conducted, using a pretested questionnaire to collect data from 239 university students in Kavango east region. A proportionate stratified random sampling was used to sample students from the three faculties on campus. Data were analysed with a Statistical Programme of Social Sciences.

The overall response rate was $75 \%$ (239) from a total of 318 respondents. Mean age was 21.4 years, respondents comprised of $155(64.9 \%)$ females and $84(35.1 \%)$ males. Almost all respondents $(94.5 \%)$ know that malaria is transmitted by mosquitoes and $80 \%$ of respondents indicated that malaria is preventable. Usage of mosquito net was the most commonly known preventive measure, indicated by 224 (94\%) of respondents. The vast majority of respondents 227 (95\%) agreed that the appropriate method to prevent self from getting malaria is to prevent mosquito bites. Surprisingly $80(33 \%)$ of the respondents believe that only children and pregnant women get malaria and therefore it's only them who need preventive measures. Only $43(18 \%)$ of the respondents always sleep under mosquito nets to prevent themselves from getting malaria. It was concluded that university students in Kavango east region have good knowledge on malaria prevention measures. Although there were some misconceptions noted, especially on the identification of population at risk of malaria, the attitudes on malaria prevention are generally satisfactory. However, the knowledge and attitudes do not reflect in the students' practices.
\end{abstract}

Keywords: malaria prevention, preventive measures, public health, university students, students welfare

\section{Introduction}

Malaria continues to be a major cause of morbidity and mortality in many topical parts of the world, despite the universal efforts to get rid of the disease (World Health Organization, WHO, 2017). It is reported that there were 219 million cases of malaria worldwide in 2017 and the African region reported most global cases of malaria, followed by the South-East Asia Region and the Eastern Mediterranean Region (WHO, 2018).The World Health Organization (2018) further reported that in 2017, there were an estimated 435000 malaria deaths globally. Most of these deaths happened in the African Region (93\% of reported deaths). Since 2010, the malaria deaths decreased by $58 \%$ in the Western Pacific Region and decreased by $46 \%$ in the South-East Asia Region. It is further reported that malaria cases decreased by $37 \%$ in the Region of the Americas and by $6 \%$ in the Eastern Mediterranean Region. In 2015, 53 countries in the European Region were reported to be malaria-free, with at least one year of zero locally-acquired cases. Children under the age of five years are predominantly at risk of malaria infection. In 2017, malaria claimed lives of 266000 under-fives globally and this stands for $61 \%$ of all reported deaths (WHO, 2018). The plasmodium falciparum malaria parasite is most prevalent in the WHO African region and is known to be transmitted by female anopheles mosquitoes.

Although malaria can be prevented and cured, it remains a big health concern to many communities in the world, especially in Sub-Saharan African. According to the Namibian Ministry of Health and Social Services (MoHSS) (2014), malaria remains a public health concern in Namibia and it is prevalent to many regions, including Zambezi, Kavango east, Kavango west, Ohangwena, Omusati, Oshana, Kunene, Oshikoto and parts of the Otjozondjupa and 
Omaheke. According to Centres for Disease Control and Prevention (CDC) (2015), global preventive measures of malaria are; sleeping under insecticide-treated mosquito nets (ITNs), intermittent preventive treatment of malaria in pregnant women (IPTp), intermittent preventive treatment of malaria in infancy (IPTi), indoor spraying, avoiding standing water, cutting long grasses promote education and public awareness and environmental management to reduce breeding sites.

The MoHSS (2014) reported the national preventive measures, which include indoor residual spraying, sleeping under mosquito nets, draining of stagnant water, and environmental management to reduce breeding sites cutting long grasses, promote education, public awareness of malaria, cutting of bushes around the houses, using chemoprophylaxis, closing windows and using repellent coils and creams to keep mosquitoes. In 2017, malaria caused deaths of twenty-two people in Namibia, of which five-teen are from Kavango east and west regions. Out of 6500 cases reported in Namibia, 4600 cases were reported specifically from Kavango east and Kavango west regions (MoHSS, 2017). A rise in Malaria cases were reported in the following regions of the country: Kavango East and West reported $78.9 \%$ of the total reported cases, $10.8 \%$ were from Zambezi region and $7.6 \%$ were from Ohangwena region. The regions with high prevalent rates of malaria share borders with Angola, where malaria is more prevalent than in Namibia (MoHSS, 2018). Despite the huge burden of malaria in Kavango regions, the use of preventative measures is currently limited. To successfully mobilise the community, health care workers should identify information the community members have on malaria prevention for messages to adopted to the identified needs.

Despite the efforts of the MoHSS to eliminate malaria, morbidity and mortality remain a challenge. Kavango east and west regions are typical case studies of communities with the challenges of high morbidity due to malaria. During March 15-22, 2017, 16425 people were tested for malaria in the two Kavango regions and out of this number 865 people tested positive (MoHSS, 2017). The increase in malaria cases is influenced by climatic and environmental factors. The kavango east region is one of the highly populated regions in the country and is home to majority of students at higher education institutions, these students are at high risk of malaria because they reside in a bushy environment. The presence of Kavango river along Rundu town promote mosquitoes to multiply and spread malaria, so it was of outmost importance to assess malaria prevention knowledge, attitudes and practices among university students in kavango east region.

\subsection{Research Setting}

The study was conducted at the university campus located in Kavango east region, Namibia. The campus is home to 1944 students and its located 10 minutes' drive from the nearest town and the river which border Namibia and Angola. The campus offers programmes under three faculties, namely: the Faculty of Economics and Management Sciences, the Faculty of Education and as of 2017, the Faculty of Health Sciences.

\subsection{Research Design}

The study use a quantitative descriptive cross-sectional design, it was deemed suitable as it allows for data to be collected at one point in time and it involves no follow-up of the participants (Brink, van Rensburg, \& van der Walt, 2012).

\section{Research Methods}

\subsection{Population and Sampling}

The study population was students registered at the university campus for academic year 2018 and it comprised of $1944(\mathrm{~N}=1944)$ students. The study used a proportionate stratified random sampling (de Vos, Strydom, Fouche, \& Delport, 2011), a total of $331(\mathrm{n}=331)$ sample was calculated according to Sekaran \& Bougie (2013) formula. The researcher drew 15\% of 331 (49) students from the Faculty of Economics and Management Sciences, Faculty of Education $73 \%$ of 331 (241) and 12\% of 331 (40) students to represent the Faculty of Health Sciences. Lastly the researchers used a fishbowl technique to select participants from each faculty randomly, by putting their identification numbers in the bowl and drawing them out one by one until the preferred representative sample per faculty was reached.

\subsection{Data Collection}

A pre-tested and self-administered questionnaire was used to collect data from study respondents. The questionnaire comprised of three sections, namely, the demographic information, knowledge about malaria preventive measures and lastly attitudes and practices of malaria prevention. The data was collected during the period August to October 2018. A total of 331 questionnaires were prepared and were distributed to sampled students, however 13 sampled students refused to give consent to participate. A total of 239 questionnaires were 
returned for analysis, out of 318 who gave consent to participate in the study. This represents a $75 \%$ response rate, which was considered as satisfactory. To ensure validity the researchers conducted a pilot study to pre-test the instrument for clarity. In addition, the questionnaire was reviewed by an expert in the field prior to data collection. To ensure reliability the researcher gave the same individuals an instrument on two occasions within a relatively short period of time and examined these individual responses for similarities.

\subsection{Data Analysis}

The researcher used Statistical Programme of Social Sciences (SPSS) version 24 to analyse the data. This enable the researchers to summarise the results and to reduce, organise and give meaning to the data that was be obtained from the questionnaires (Grove, Gray, \& Burns, 2015). Descriptive statistics such as frequencies and mean were used to describe the data. Thereafter, the data was presented in tables and charts. The students' knowledge on malaria prevention was considered excellent when they scored $81-100 \%$ on the questions on knowledge. A satisfactory/good score was given for $71-80 \%$, poor for $51-70 \%$ and unsatisfactory knowledge when scored $50 \%$ and below. The students' attitudes were categorized as positive when agreed to six positive statements and negative when agreed to less than six statements.

\subsection{Ethical Considerations}

Ethical clearance and permission to conduct this study was obtained from the university campus research committee. The researchers were guided by ethical principles that are based on human rights and protection of respondents during research. These principles are: respect of person, beneficence, justice, voluntary participation, confidentiality and anonymity (Brink, van Rensburg, \& van der Walt, 2012).

\section{Results}

\subsection{Characteristics of the Respondents}

Out of 239 respondents who completed the questionnaires, a total of $124(51.9 \%)$ were from the Faculty of Education, 60 (25.1\%) from the Faculty of Economics and Management Sciences and 55 (23\%) from the Faculty of Health Sciences. The overall mean age was 21.4 years and the respondents' age ranges $18-45$ years old. Female comprised of $155(64.9 \%)$ and males 84 (35.1\%). Majority of respondents (180) representing $75 \%$ resides in the university hostel, while $59(25 \%)$ resides outside the university hostel. This is because the university hostel only accommodates a few students. A total of $210(87.9 \%)$ indicated that their houses are constructed from bricks and iron sheets, this also include university hostels while 29 (12.1\%) reside in traditional houses constructed from thatch, reed and mud. Table 1 below indicates the characteristics of respondents.

Table 1. Characteristics of respondents

\begin{tabular}{ll}
\hline Variables & Total $\mathbf{( n = 2 3 9 )}$ \\
\hline Age & \\
Mean & $\begin{array}{l}21.4 \text { years } \\
18-45 \text { years }\end{array}$ \\
Range & \\
\hline Gender & $155(64.9 \%)$ \\
Female & $84(35.1 \%)$ \\
Male & \\
\hline University Faculties & $124(51.9 \%)$ \\
Education & $60(25.1 \%)$ \\
Economic and Management Sciences & $55(23 \%)$ \\
Health Sciences & \\
\hline Materials of houses & $210(87.9 \%)$ \\
Bricks and iron sheets & $29(12.1 \%)$ \\
Thatch, reed and mud & \\
\hline
\end{tabular}




\subsection{University Students' Knowledge About Malaria Prevention}

Ninety four percent (94\%) of respondents had heard about malaria before and only $6 \%$ of respondents had not heard about malaria prior to participating in the study. Almost all respondents (94.5\%) know that malaria is transmitted by mosquitoes, while $5 \%$ of respondents indicated that malaria is transmitted by other vectors such as flies. Only $0.5 \%$ of the respondents do not know the vector that transmits malaria. Majority of respondents (80\%) indicated that malaria is preventable, while only $15 \%$ indicated that malaria is unpreventable. Only $5 \%$ of respondents indicated that they don't know if malaria can be prevented. The figure below indicates responses on whether or not malaria can be prevented.

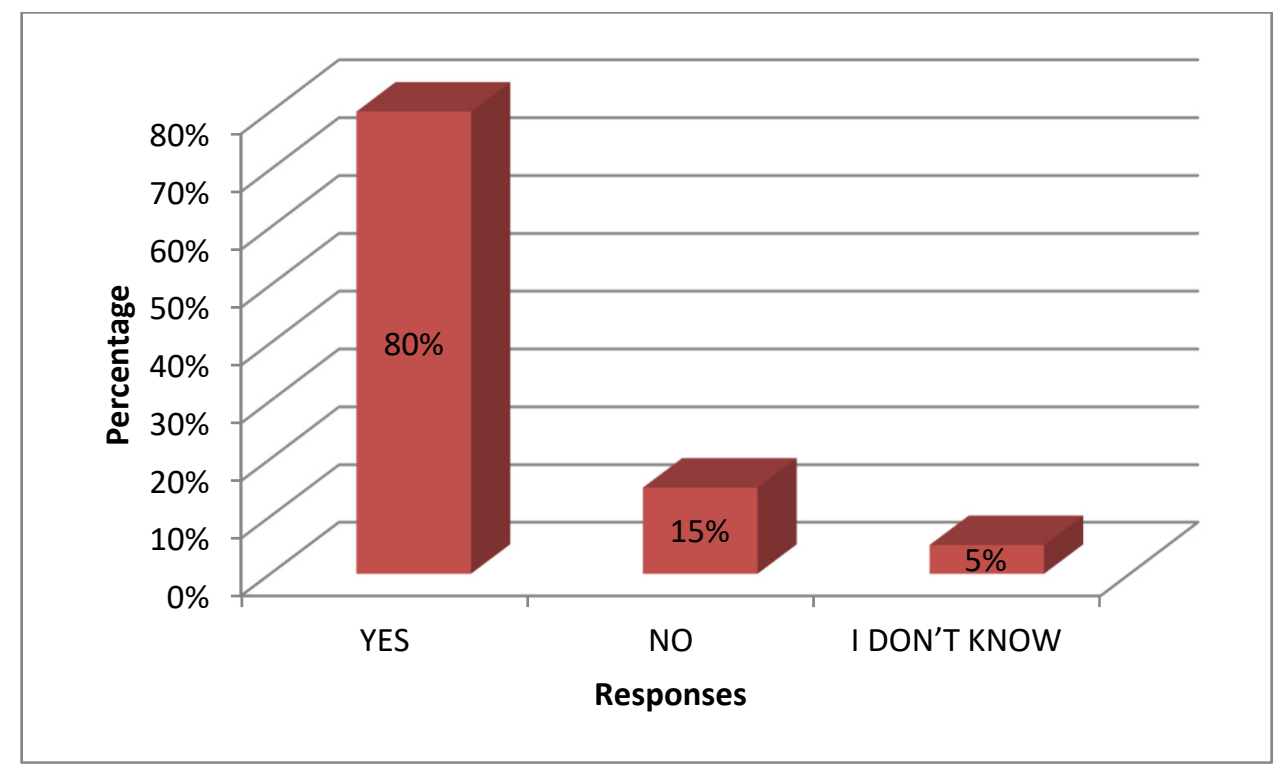

Figure 1. University students' indication on whether or not malaria can be prevented

Furthermore, regarding the knowledge of malaria preventive measures, usage of mosquito nets was the most commonly known preventive measure, indicated by 224 (94\%) of respondents. The least known malaria preventive measure is the usage of insect repellent creams. The table below shows malaria preventive measures known by the university students.

Table 2. Knowledge of university students on malaria preventive measures

\begin{tabular}{ll}
\hline Item answered & No (\%) $\mathbf{n}=\mathbf{2 3 9}$ \\
\hline Usage of mosquito nets & $224(94 \%)$ \\
Indoor insecticide spraying & $203(85 \%)$ \\
Cleaning the house surroundings & $193(81 \%)$ \\
Draining stagnant water & $138(58 \%)$ \\
Wearing long sleeves & $163(68 \%)$ \\
Making fire/smoke using traditional herbs & $134(56 \%)$ \\
Closing houses' windows and doors & $184(77 \%)$ \\
Burning mosquito repellent coils & $184(77 \%)$ \\
Use of insect repellent creams & $175(73 \%)$ \\
\hline
\end{tabular}

\subsection{University Students' Attitudes Towards Malaria Prevention}

The majority of respondents 227 (95\%) agreed that the best way to prevent self from getting malaria is to avoid mosquito bites while $7(2.9 \%)$ disagreed to that statement. While $5(2.1 \%)$ were neutral. Majority of the 
respondents 233 (97.5\%) agreed that sleeping under a mosquito net is one way to prevent malaria and only 6 (2.5\%) disagreed to mosquito nets being a way to prevent malaria. In addition, $39(16.3 \%)$ reported being able to treat themselves if they get malaria and majority 200 (83.7\%) disagreed to this. Surprisingly 80 (33\%) of the respondents believe that only children and pregnant women are at high risk of getting malaria and therefore it's only them who need preventive measures. While $157(65.7 \%)$ know that malaria preventive measures are applicable to all age groups.

Moreover $22(9.2 \%)$ of the respondents believe that uninfected persons should avoid close contact with person who has malaria and almost all of the respondents $216(90 \%)$ know that people should not avoid close contact with someone who has malaria. One respondent did not respond to this statement. Furthermore $69(28 \%)$ believe that sleeping under a mosquito net puts one at higher risk of suffocation and $169(70.7 \%)$ respondents disagreed to this statement. Only one respondent ( $0.4 \%)$ gave neutral response to this statement.

Table 3. Attitudes of university students on malaria prevention

\begin{tabular}{|c|c|c|c|c|c|c|}
\hline & \multicolumn{2}{|c|}{ Agree } & \multicolumn{2}{|c|}{ Disagree } & \multicolumn{2}{|c|}{ Neutral } \\
\hline & $\mathbf{n}$ & $\%$ & $\mathbf{n}$ & $\%$ & $\mathbf{n}$ & $\%$ \\
\hline $\begin{array}{l}\text { The best way to prevent myself getting Malaria is to avoid getting } \\
\text { mosquito bites }\end{array}$ & 227 & 95 & 7 & 2.9 & 5 & 2.1 \\
\hline $\begin{array}{l}\text { I believe sleeping under a mosquito net during the night is one way } \\
\text { to prevent myself getting Malaria }\end{array}$ & 233 & 97.5 & 6 & 2.5 & 0 & 0 \\
\hline I am sure that I can treat myself if I get Malaria & 39 & 16.3 & 200 & 83.7 & 0 & 0 \\
\hline $\begin{array}{l}\text { Malaria preventive measures are only applicable to children and } \\
\text { pregnant women }\end{array}$ & 80 & 33.5 & 157 & 65.7 & 2 & 8 \\
\hline $\begin{array}{l}\text { One can recover spontaneously from Malaria without any } \\
\text { treatment }\end{array}$ & 13 & 5.4 & 219 & 91.6 & 7 & 3 \\
\hline $\begin{array}{l}\text { If someone has got Malaria, people should avoid having close } \\
\text { contact with him/he as a preventive measure }\end{array}$ & 22 & 9.6 & 216 & 90 & 1 & 0.4 \\
\hline $\begin{array}{l}\text { I might be at a greater risk of getting Malaria if I work and sleep } \\
\text { overnight in the garden or forest }\end{array}$ & 194 & 81.2 & 44 & 18.4 & 1 & 0.4 \\
\hline $\begin{array}{l}\text { I might be at greater risk of suffocation if I sleep under the } \\
\text { mosquito net }\end{array}$ & 69 & 28.9 & 169 & 70.7 & 1 & 0.4 \\
\hline
\end{tabular}

\subsection{University Students Practices of Malaria Prevention}

A total of 98 (41\%) of the respondents use mosquito nets sometimes, similarly 98 (41\%) never used mosquito nets before and only $43(18 \%)$ of the respondents always sleep under mosquito nets to prevent themselves from getting malaria. Forty six percent ( $46 \%$ ) of the respondents sometimes check and repair holes of their mosquito nets while only $13 \%$ always check and repair holes of their mosquito nets. The Figure below indicates university students' responses on usage of mosquito nets. 


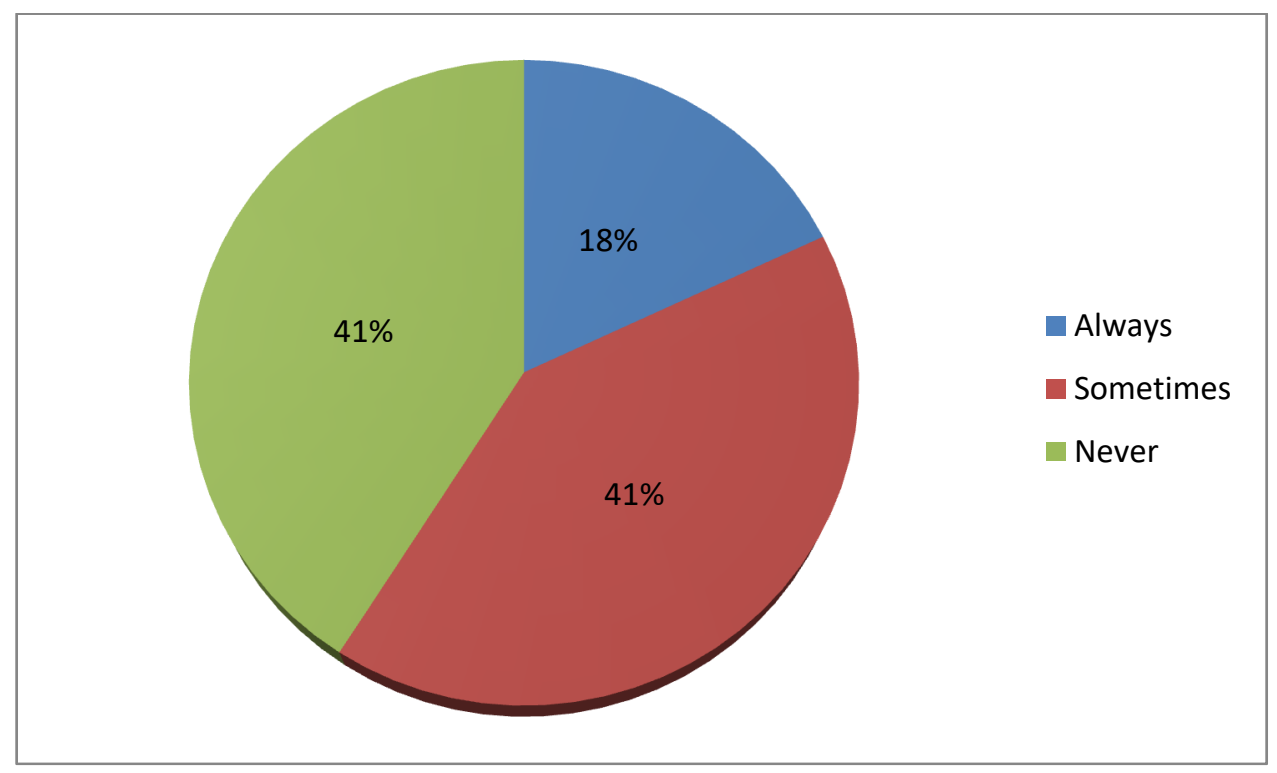

Figure 2. University students' usage of mosquito nets

Furthermore, only $15 \%$ of the respondents' use insect repellent coils always to prevent them from malaria. About half of the respondent's only use repellent coils sometimes and $35 \%$ never used repellent coils before. About more than half of the respondents (51\%) sometimes use anti mosquito spray in their rooms, $22 \%$ always use and $27 \%$ never use anti-mosquito spray in their rooms. The use of anti-mosquito sprays was indicated as mostly used method to prevent malaria among university students. Only $17 \%$ of respondents indicated that they always cut and clear bushes around their houses, $43 \%$ sometimes do cut and clear bushes and $40 \%$ do not cut the bushes at all. Moreover, the study revealed that $41 \%$ of the respondents sometimes clean stagnant water near their houses or hostels, $23 \%$ always clean stagnant water and 35\% do not clean stagnant water near their houses.

\section{Discussion}

This descriptive cross-sectional study provided information on the knowledge, attitudes and practices on malaria prevention among university students in Kavango east region. The students' knowledge on malaria prevention was observed to be satisfactory as $74 \%$ questionnaire were rated as "good" grade because respondents provided correct answers. There was no difference revealed on knowledge of malaria prevention measures among students of different age groups in this study. This is against the results of Yin et al., (2013) who reported significant differences of awareness of malaria prevention among different age groups. About $94 \%$ of the respondents in this study reported mosquito nets as the most common protective method against malaria. This is similar results of a study conducted in in Rural Northwest of Tanzania which also revealed the use of bed nets as a popular malaria preventive measure (Mazigo et al., 2010). The second most known preventive measure was the use of anti-insecticide sprays in bedrooms which was reported by $85 \%$ of the respondents. The knowledge of measures to prevent mosquito breeding by cleaning the house surroundings was reported by $81 \%$ and draining stagnant water was reported by $58 \%$, by wearing long sleeved clothing was reported by $68 \%$, by making fire and smoke $56 \%$, by closing windows and doors $77 \%$, by use of repellent coils $77 \%$ and by use of repellent creams $73 \%$. This is similar to the study that was conducted in Cameroon which revealed correct measures of preventing malaria such as: use of mosquito bed nets and insecticidal sprays, keep the environment clean, drain stagnant water and clear bushes around homes (Aderaw \& Gedefaw, 2013).

Positive attitudes were reported by students on most of the preventive measures of malaria, however the study also shows that there is certain misconceptions existing among the study population. Thirty three percent (33.5\%) agreed that only children and pregnant women are at risk of malaria. This result contradicts report by WHO (2018) which states that nearly everyone is at risk of malaria although some population groups are at considerably higher risk of contracting malaria and developing severe disease than others and these groups are : children under five and all immune-compromised people. Twenty eight percent (28\%) of the respondent believe that they are at higher risk of suffocation when they sleep under mosquito nets. This is consistent with findings of Acosta, Koenker, Loll, \& Scandurra (2013) that revealed that most of the respondents mentioned feelings of discomfort such as feelings of suffocation or being too hot while sleeping under mosquito nets. The results are also supported by findings of 
Okoli and Enna (2014), who stated that some people incorrectly believe that the mosquito nets might obstruct their breathing, and that sleeping beneath it could therefore lead to death. Furthermore, some respondents are undermining the severity of malaria as $(10 \%)$ of them disagreed that malaria is a serious life-threatening disease and agreed that they can treat themselves when they get it. This is an indication that comprehensive health education needs to be given in order to correct these misunderstandings.

The most preventive measure practiced by students $(51 \%)$ to prevent themselves from malaria is the use of insecticide sprays in their rooms. This study revealed other preventive measures as follows; sleeping under mosquito nets (18\%), although only $13 \%$ of the respondents always check and repair holes of their mosquito nets and the use repellent coils (15\%). It is also shown in the study done in Nigeria that the following preventive measures were used as follows among 300 students: netted windows, treated nets, sprays, chemoprophylaxis and other methods (Zablon et al., 2015). This finding is also similar to Essé et al., (2008) who found that majority of respondents claimed to be using measures to avoid mosquito bites including insecticide sprays, bed nets and fumigation with burning coils for malaria prevention in Côte d'Ivoire. Compared to a study conducted at a tertiary institution in west Africa where malaria cases are also high, students were reported to buy combined anti malaria drug as a preventive measures (Adeyemo, Okpala, Oyana, \& Imoukhuede, 2014); however the use of malaria drugs were not reported in this study. Limited use of repellent coils in the current study is quite surprising because they are available from the local markets at affordable prices in comparison to insecticide sprays which are expensive.

\section{Conclusion}

It is concluded from the study that university students in Kavango east region has good knowledge about malaria prevention measures. Furthermore, university students are aware about malaria transmission method. Although there were some misconceptions noted, especially on the identification of population at risk of malaria, the attitudes on malaria prevention are generally satisfactory. This is evidenced by the majority of respondents who agreed that the best way to prevent malaria is to protect themselves from mosquito bites. However, the knowledge and attitudes do not reflect in the students' practices, which revealed that only $18 \%$ of respondents always sleep under mosquito nets. This is despite that mosquito nets are freely distributed to inhabitants of regions prone to malaria, including Kavango east.

\section{Recommendations}

This study recommends the Ministry of Health and Social Services through the malaria prevention division to provide a comprehensive health education to the university students and general populations in order to correct misconceptions on malaria and to stress more on usage of preventive measures. This should also include information on correct usage and maintenance of mosquito nets. Furthermore, it's recommended that university should make use of peer teaching, especially the students from Faculty of Health Sciences to educate other students on different health aspects, including preventive measures of infectious diseases.

\section{Study Limitations}

The overall response rate was $75 \%$, this could be due to busy schedules of university students as the data was collected during period students were preparing for summative assessments. Due to busy schedules and time factors, students were given options to take questionnaires home and return them next day, therefore there was a possibility of obtaining responses from other sources such a family members, non-participating colleagues or internet.

\section{Acknowledgements}

The authors are thankful to all students who participated in the study, despite their busy schedules.

\section{Authors' Contributions}

This project was carried out by VJ as part of the Bachelor Nursing Science (Clinical) programme; therefore she proposed the study, collected data, analysis and wrote final report. VN supervised the project, drafted and reviewed the manuscript.

\section{Competing Interests Statement}

There is no conflict of interests expressed by the authors.

\section{References}

Acosta, A., Koenker, H., Loll, D., \& Scandurra, L. (2013). Uganda Culture of Mosquito Net Use Study. Johns Hopkins Bloomberg School of Public Health Center, (October 2012), 1-29. Retrieved from 
http://www.networksmalaria.org/sites/default/files/Uganda Culture of Net Use Phase One Report_final.pdf

Aderaw, M., \& Gedefaw, Z. (2013). Knowledge, Attitude and Practice of the Community towards Malaria Prevention and Control Options in Anti-Malaria Association Intervention Zones of Amahara National Regional State, Ethiopia. Journal of Tropical Diseases, 01(03), 1-7. https://doi.org/10.4172/2329-891X.1000118

Adeyemo, F. O., Okpala, P. U., Oyana, E. N., \& Imoukhuede, M. (2014). Malaria Infection amongst Students of the University of Benin, Edo State. International Journal of Recent Scientific Research, 5(9), 1529-1532. Retrieved from www.recentscientific.com

Brink, H. I., van Rensburg, G., \& van der Walt, C. (2012). Fundamentals of Research Methodology for Health Care Professionals (3rd ed.). Cape Town: Juta.

CDC. (2015). CDC-Parasites-Malaria. Retrieved December 25, 2018, from https://www.cdc.gov/parasites/malaria/index.html

de Vos, A. S., Strydom, H., Fouche, C. B., \& Delport, C. (2011). Research at grass roots for the social sciences and human service professions. Van Schaick (4th ed.). Pretoria: Van Schaick.

Essé, C., Utzinger, J., Tschannen, A. B., Raso, G., Pfeiffer, C., Granado, S., ... Obrist, B. (2008). Social and cultural aspects of "malaria" and its control in central Côte d'Ivoire. Malaria Journal, 7(January). https://doi.org/10.1186/1475-2875-7-224

Grove, S. K., Gray, J. R., \& Burns, N. (2015). Understanding nursing research: Building an evidence-based practice. Elsevier (6th ed). Elsevier Ltd.

Mazigo, H. D., Obasy, E., Mauka, W., Manyiri, P., Zinga, M., Kweka, E. J., ... Heukelbach, J. (2010). Knowledge, Attitudes, and Practices about Malaria and Its Control in Rural Northwest Tanzania. Malaria Research and Treatment, 2010, 1-9. https://doi.org/10.4061/2010/794261

MoHSS. (2014). Namibia 2013 Demographic and Health Survey. Windhoek. Retrieved from https://dhsprogram.com/pubs/pdf/fr298/fr298.pdf

MoHSS. (2017). Malaria cases 2017. Rundu.

MoHSS. (2018). Malaria cases 2018. Rundu.

Okoli, C. A., \& Enna, M. (2014). A cross-sectional study on knowledge of, attitudes towards and practice of malaria prevention and control measures in central Nigeria. Southern African Journal of Epidemiology and Infection, 29(1), 37-42. https://doi.org/10.1080/23120053.2014.11441565

Sekaran, U., \& Bougie, R. (2013). Research Methods for Business: A Skill-Building Approach. New York: Wiley.

World Health Organization [WHO]. (2017). WHO|Fact Sheet: World Malaria Report 2016. Geneva: World Health Organization. Retrieved from https://www.who.int/malaria/media/world-malaria-report-2016/en/

World Health Organization [WHO]. (2018). World Malaria Report 2018. Geneva. Retrieved from www.who.int/malaria

Yin, J.-H., Wang, R.-B., Xia, Z.-G., Zhou, S.-S., Zhou, X.-N., Zhang, Q.-F., \& Feng, X.-Y. (2013). Students' awareness of malaria at the beginning of national malaria elimination programme in China. Malaria Journal, 12(237), 1-4. https://doi.org/10.1186/1475-2875-12-237

Zablon, K. N., Kakilla, C., Lykina, T., Minakova, V., Chibago, A., \& Bochkaeva, Z. (2015). Prevalence of Plasmodium falciparum Malaria among Pregnant Students in Dodoma Region, Tanzania: No Cases Have Been Detected. Malaria Research and Treatment, 2015, 1-5. https://doi.org/10.1155/2015/473203

\section{Copyrights}

Copyright for this article is retained by the author(s), with first publication rights granted to the journal.

This is an open-access article distributed under the terms and conditions of the Creative Commons Attribution license (http://creativecommons.org/licenses/by/4.0/). 